\title{
ASSESSMENT OF THE DIAGNOSTIC POTENTIAL OF CLINOTECH TB SCREEN TEST FOR DIAGNOSIS OF PULMONARY TUBERCULOSIS IN NIGERIA
}

\author{
EKUNDAYO $^{1}$, E. O., ABBEY ${ }^{2}$, S.D. AND ACHI ${ }^{1}$, O.K. \\ ${ }^{1}$ Department of Microbiology, College of Natural and Applied Sciences, Michael Okpara University of Agriculture, Umudike, \\ Abia State. ${ }^{2}$ Department of Medical Laboratory Science, Faculty of Science, Rivers State University of Science and Technology, \\ Nkpolu, Port Harcourt
}

Correspondence to: E. O. Ekundayo (emma_ekundayo@yahoo.com).

\begin{abstract}
The Clinotech TB Screen test, a $3^{\text {rd }}$ generation multi-antigen rapid chromatographic immunoassay for detection of IgG antibodies in serum against recombinant protein antigens $38 \mathrm{kDa}, 16 \mathrm{kDa}$ and $6 \mathrm{kDa}$, was assessed for its diagnostic potential for diagnosis of active pulmonary TB in routine TB control programme in Abia State, Nigeria. The overall sensitivity and specificity of Clinotech TB Screen test were $24.1 \%$ and $87.8 \%$ (95\% Confidence intervals [CI]: 14.7-33.5\% and 80.6-95.0\%) respectively. The positive and Negative Predictive Values (PPV and NPV) were $79.2 \%$ and $37.5 \%$ respectively. The performance of the test was inferior to that of the sputum smear microscopy which had a sensitivity of $50.0 \%(95 \% \mathrm{CI}, 39.0 \%-61.0 \%)$ and specificity of $\mathbf{9 2 . 3 ( 9 5 \%}$ CI: 86.4-98.2\%). In 37 culture positive smear positive PTB cases, Clinotech TB Screen test was positive in 18(48.65\%). The rapid test showed a very low degree of sensitivity in smear -negative culture positive PTB cases; detecting just one $(2.38 \%)$ out of 42 cases. These results indicate that the diagnostic value of Clinotech TB Screen test for routine diagnosis of PTB in this setting is limited.
\end{abstract}

Key words: Tuberculosis, serological tests, immunochromatographic tests, rapid TB tests

\section{INTRODUCTION}

Diagnosis is a key element in the global plan to control TB (1). Rapid and accurate diagnosis is critical to effective TB care and interruption of transmission (2). However, lack of simple, rapid and accurate diagnostic tests remains one of the greatest constraints for effective control of $\mathrm{TB}$, especially in developing countries where the highest burdens of TB are found and facilities for performing traditional laboratory diagnosis are inadequate or not available (3). Furthermore, the existing conventional diagnostic methods such as sputum smear microscopy (SSM), culture and chest radiography have technical and operational characteristics that limit the quality and the scope of their applications in developing countries (4).

Rapid Diagnostic tests (RDTs) employing immunological principles to detect antibodies have recently been developed. These tests are attractive because they are easy to use, rapid, and relatively inexpensive and without the need for sophisticated laboratory infrastructure (5). They hold out a great promise of providing the developing countries with an invaluable way to quickly and cheaply diagnose infectious diseases (6).
Many antigens of Mycobacterium tuberculosis have been isolated, purified and tested for their potential for development of rapid serological tests (7). Some of these antigens have been employed in developing commercial serological TB tests (8). Clinotech TB Screen from Clinotech Diagnostics and Pharmaceuticals, Inc, Canada, is one of such tests being distributed in several developing countries including Nigeria. Evaluation of several rapid TB serological tests showed that the tests have variable performance in different epidemiological settings (5). We conducted the present study to assess the diagnostic performance characteristics of Clinotech TB Screen for diagnosis of pulmonary tuberculosis in Abia State, Nigeria.

\section{MATERIALS AND METHODS}

\section{Study Participants.}

The study participants were recruited from TB suspects, defined as patients with cough of at least 3 weeks' duration referred to the Leprosy and Tuberculosis Referral Hospital, Uzuakoli, Bende Local Government Area (LGA) and Aba South LGA Health Office, Aba, two major directly observed treatment short course (DOTS) centres within the Abia State TB Control Programme, to undergo sputum smear 
microscopy investigation for pulmonary tuberculosis (PTB) between November 2008 and February 2010. Eligible study participants were TB suspects 15 years and above who were not on antituberculosis treatment at the time of recruitment. The study included $150 \mathrm{~TB}$ suspects who met the inclusion criteria and were prospectively enrolled as study participants. Informed consent for participation was obtained from the study participants. The study protocol was approved by the Ethical Committee of the Federal Medical Centre (FMC), Umuahia, Abia State.

Three sputum samples, one spot sample on the first day of patient visit, an early morning sample brought from home the next day, and the second spot sample collected when the patient brought the early morning specimen, were obtained from each study participant. Venous blood samples were also collected from the TB suspects for serological TB tests. The blood samples were collected into anticoagulant free plastic tubes from which the sera were later separated.

\section{Sputum smear microscopy and sputum culture}

For sputum smear microscopy, direct sputum smears were made from the sputum samples and stained by the Ziehl-Neelsen staining technique for acid-fast bacilli (AFB). For culture, the sputum samples were decontaminated using modified Petroff"s alkali method and concentrated by centrifugation at $3,000 \mathrm{rpm}$ for 30 minutes. The processed sputum samples were cultured on Lowenstein-Jensen (LJ) medium and incubated at $37^{\circ} \mathrm{C}$ and examined for growth daily for the first 7 days and twice weekly thereafter up to $8^{\text {th }}$ week until a definite result was obtained. The slants that did not showed any growth after 8 weeks of incubation were recorded as culture negative.

\section{Clinotech TB Screen test}

The Clinotech TB Screen test was manufactured by Clinotech Diagnostics and Pharmaceuticals, Inc, Canada and distributed in Nigeria by Clinotech Nigeria Limited, Lagos. The Clinotech TB Screen test is a $3^{\text {rd }}$ generation chromatographic immunoassay (CIA) using direct binding double sandwich antibody (Ab-Ag-Ab) principle for direct qualitative detection of TB antibody in human serum or plasma. The test is a multi-antigen test containing recombinant $M$. tuberculosis antigens $38 \mathrm{kDa}, 16 \mathrm{kDa}$ and $6 \mathrm{kDa}$ conjugated to colloidal gold particles and immobilized on the test membrane.

The test was done according to the manufacturer's instructions contained in the package insert. The test device was removed from the pouch and placed on a clean, dry level surface. Using the plastic pipette provided in the test pouch, serum was drawn up to the $100 \mu \mathrm{l}$ mark on the pipette and applied into the sample application well. The test result was read at 15 minutes after sample application and interpreted according to the manufacturer's instructions.

\section{RESULTS}

Clinotech TB Screen test was compared with sputum smear microscopy in 150 TB suspects. The sputum samples of $52(37.14 \%)$ of the patients were positive for AFB. Clinotech TB Screen test was positive in 26 $(50.00 \%)$ of the 52 smear positive cases and $6(6.12 \%)$ of the 98 smear negative cases. In total the Clinotech TB Screen was positive for anti-TB antibodies in 32 $(22.86 \%)$ of the total study participants. The ability of the test to detect the smear-positive cases according to AFB grading is shown in Table 1 . The ability of the Clinotech TB Screen test to identify the culture positive PTB cases is shown in Table 2. In 37 culture and smear positive PTB cases, the test was positive in $18(48.65 \%)$ and in $1(2.38 \%)$ of 42 culture-positive but smear-negative PTB cases.

\section{TABLE 1: PERFORMANCE OF CLINOTECH TB SCREEN TEST IN SPUTUM SMEAR POSITIVE PTB PATIENTS IN ABIA STATE}

\begin{tabular}{|c|c|c|}
\hline AFB Grade & $\begin{array}{l}\text { No. }(\%) \\
\text { Positive } \\
\text { by SSM }\end{array}$ & $\begin{array}{l}\text { No. }(\%) \\
\text { Positive } \\
\text { by Clinotech } \\
\text { TB Screen test }\end{array}$ \\
\hline $\begin{array}{l}\text { Scanty (1- } \\
\text { 9) }\end{array}$ & 6/52 (11.54) & 1/6 (16.67) \\
\hline $1+(10-99)^{b}$ & $14 / 52(26.92)$ & $9 / 14(64.29)$ \\
\hline $2+(1-10)^{c}$ & $16 / 52(30.77)$ & $9 / 16(56.25)$ \\
\hline $3+(>10)^{d}$ & $16 / 52(230.77)$ & $7 / 16(43.75)$ \\
\hline TOTAL & $52(100)$ & $26 / 52(50.00)$ \\
\hline $\begin{array}{l}\text { a } 1-9 \mathrm{AF} \\
\text { b } 10-99 \mathrm{~A} \\
\text { c } 1-10 \mathrm{Al} \\
\text { d }>10 \mathrm{AF} \\
\text { SSM- S }\end{array}$ & $\begin{array}{l}\text { 100HPF (high } \\
\text { FB/100HPF } \\
\text { 3/HPF } \\
\text { /HPF } \\
\text { utum smear mid }\end{array}$ & ower field) \\
\hline
\end{tabular}

The overall performance of the test against a reference standard of sputum culture is presented in Table 3. The sensitivity and specificity were $24.1 \%$ and $87.8 \%$ respectively. The positive and negative predictive 
values were $79.2 \%$ and $37.5 \%$ respectively. The combination of the results of Clinotech TB Screen test with those of smear microscopy resulted in the improvement of the sensitivity from $24.1 \%$ to $51.4 \%$ but with a corresponding decrease of specificity from $87.8 \%$ to $80.9 \%$.

TABLE 2: DETECTION OF CULTURE POSITIVE PTB CASES BY CLINOTECH TB SCREEN TEST

\begin{tabular}{|c|c|c|c|c|}
\hline Diagnostic category & $\begin{array}{l}\text { No. of } \\
\text { cases }\end{array}$ & No. Positive (\%) & No. Negative (\%) & $\begin{array}{l}\text { No. }(\%) \text { with } \\
\text { low signal } \\
\text { result (Faint) }\end{array}$ \\
\hline $\begin{array}{l}\text { Culture positive, smear } \\
\text { positive }(\mathrm{Cx}+\mathrm{ve}, \mathrm{Sm}+\mathrm{ve})\end{array}$ & 37 & $18(48.65)$ & $19(51.35)$ & $1(5.55)$ \\
\hline $\begin{array}{l}\text { Culture positive, smear } \\
\text { negative }(C x+v e, S m-v e\end{array}$ & 42 & $1(2.38)$ & $41(97.62)$ & $0(0)$ \\
\hline $\begin{array}{l}\text { Culture positive, smear } \\
\text { positive (*NTM) }\end{array}$ & 8 & $3(37.50)$ & $5(62.25)$ & $0(0)$ \\
\hline $\begin{array}{l}\text { Culture positive, smear } \\
\text { negative (NTM) }\end{array}$ & 4 & $2(50.00)$ & $2(50.00)$ & $0(0)$ \\
\hline
\end{tabular}

*NTM - Nontuberculous mycobacteria

TABLE 3. SENSITIVITY, SPECIFICITY, PPV AND NPV OF CLINOTECH TB SCREEN TEST IN REFERENCE TO SPUTUM CULTURE

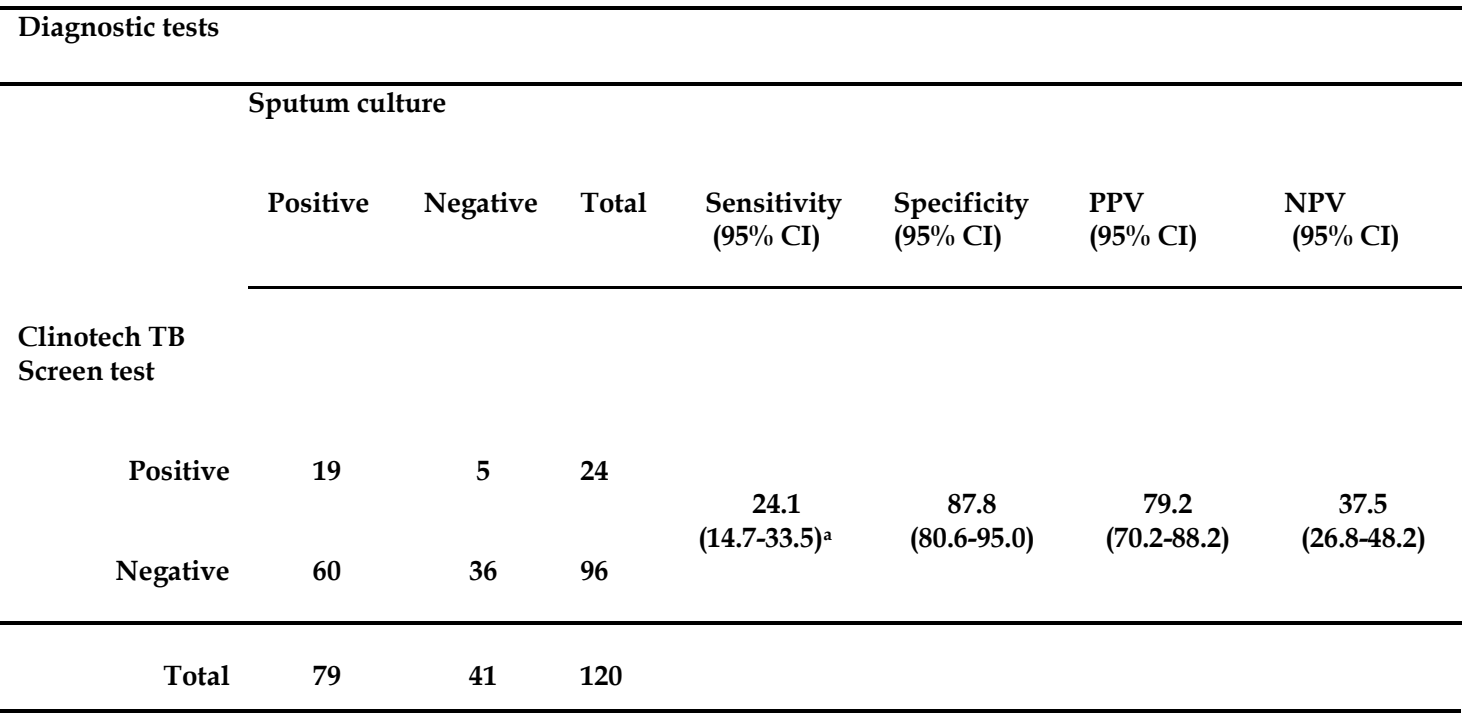

a95\% CI- 95\% Confidence Interval

PPV- Positive Predictive value

NPV- Negative Predictive Value

DISCUSSION

We have assessed the diagnostic potential of Clinotech TB Screen test for diagnosis of active pulmonary $\mathrm{TB}$ in routine $\mathrm{TB}$ control programme in Abia State, Nigeria. The performance of the test was inferior to that of the sputum smear microscopy. While the sputum smear microscopy had a sensitivity of $50.0 \%$ (95\% Confidence interval [CI], 39.0\%-61.0\%), the Clinotech TB Screen test had a sensitivity of $24.1 \%$ 
(95\% CI: $14.7 \%-33.5 \%$ ). In 37 culture positive smear positive PTB cases, Clinotech was positive only in $18(48.65 \%)$. The rapid test showed a very low degree of sensitivity $(2 \%)$, detecting just one of 42 cases of smear -negative culture positive PTB cases in this study. The overall sensitivity and specificity of Clinotech TB Screen test were $24.1 \%$ and $87.8 \%$ (95\% CI: $80.6-95.0 \%$ respectively. The positive and Negative Predictive Values (PPV and NPV) were $79.2 \%$ and $37.5 \%$ respectively. These values indicate that the diagnostic value of Clinotech TB Screen test for routine diagnosis of PTB in this setting is limited.

Previous evaluations of serological TB tests in Nigeria showed variable performance of low to moderate sensitivities. The ELISA-based Pathozyme TB EIA kits (Pathozyme-TB Complex Plus, Pathozyme Myco A, Myco M and Myco G were evaluated in Lagos by Enwuru et al. (9). These kits employed 38kDa and $16 \mathrm{kDa}$ antigens as in Clinotech TB Screen test. The authors reported sensitivities of $4 \%$ for Myco A, $24 \%$ for Myco M and $76 \%$ for Myco $G$ with specificity of $100 \%$ for Myco $G$ in smear and culture positive category. The performance of Clinotech TB Screen test in our study appeared to be lower than that of Myco $\mathrm{G}$ which is the kit in that series that was directed at detecting IgG antibodies. Ohanu et al. (10) reported the evaluation of the SmartCheck TB immunochromatographic test in a hospital-based study in Enugu, Nigeria. They used sputum smear microscopy as reference standard and compared the test with X-ray. The sensitivity was reported as $89.5 \%$ and the specificity was $77.7 \%$. It is difficult to make a direct comparison of our results with this study because we used culture as reference standard and because the identity of mycobacterial antigen used in the SmartCheck TB was not stated in the paper. Our results are similar to those of Kassa-Kelembho et al. (11) who reported a sensitivity of $20.6 \%$ and specificity of $90.3 \%$ for SDHO MTB test in Bangui, Central African Republic.

Poor diagnostic performance of rapid TB tests has been reported in several previous studies. In a study conducted by Pottumarthy et al. (12) to compare the

\section{REFERENCES}

1. Raviglione, M.C. The new Stop TB Strategy and the Global Plan to stop TB, 2006-2015. Bulletin of the World Health Organization 2007; 85 (5): 327

2. Pai, M., Ramsay, A. and O'Brien, R. Evidence-Based Tuberculosis Diagnosis. PLOS Medicine 2008; 5(7): e156.doi:10.137/journal.pmed.0050156

3. WHO/TDR Diagnostics for Tuberculosis: Global demand and Market Potential. 2006; WHO, Geneva, Switzerland

4. Perkins, M.D. and Kritski, A.L. Diagnostic testing in the control of tuberculosis. Bulletin of the World Health Organization 2002; 80 (6) 512-513. accuracy of seven antibody detection tests for diagnosis of tuberculosis in New Zealand among immigrants from countries with a high prevalence of tuberculosis, the sensitivity ranged from $16 \%$ to $57 \%$. The two immunochromatographic tests, ICT Tuberculosis and Rapid Test TB, included in that study had sensitivity of $41 \%$ and $25 \%$ respectively. The corresponding specificities were $96 \%$ and $87 \%$ respectively. The results of laboratory -based evaluation of 19 commercially available rapid diagnostic tests for TB sponsored by Special Programme for Research and Training in Tropical Diseases (TDR) between 2005 and 2006 showed that the sensitivity of the tests ranged from $0.97 \%$ to $59.7 \%$; specificity ranged from $53 \%$ to $98.7 \%$ (13). Clinotech TB Screen test was not included in the TDR study because the manufacturer declined to participate in the study. The evaluation of this test is reported for the first time in this study. Anderson et al. (14) evaluated three ELISA based TB antibody tests, InBios Active Tb Detect, IBL M. tuberculosis and Anda Biologics TB which utilized newer mycobacterial antigens: Mtb81, Mtb8, Mtb48, DPEP (MPT32) in addition to $38-\mathrm{KDa}$ protein, and two additional proprietary antigens. The sensitivity of InBios Active Tb Detect was 83.3\%, IBL M. tuberculosis had sensitivity of $5.6 \%$ and Anda Biologics TB had $83.3 \%$ with corresponding specificities of $98.9 \%, 100 \%$ and $72 \%$ respectively.

Although we found the Clinotech TB Screen test to be a rapid and easy to use test, the low sensitivity of the test makes it unsuitable for use as a stand alone test for routine diagnosis of TB in this setting.

ACKNOWLEDGEMENTS

We are grateful to the doctors, laboratory technologists and other staff of the Leprosy and Tuberculosis Referral Hospital, Uzuakoli, Aba South LGA Health office, Aba and Abia State Leprosy and Control Programme, Abia State Ministry of Health for their enormous cooperation and assistance in collecting samples for this study.

5. Steingart, K. R., Henry M., Laal, S., Hopewell, P.C., Ramsay, A., Menzies, D., Cunningham, J., Weldingh, K. and Pai, M. Commercial serological Antibody Detection Tests for the Diagnosis of Pulmonary Tuberculosis: A systematic Review. PLOS Medicine 2007; 4(6): 1041- 1060, e202.doi:10.1371/journal.pmed.0040202

6. Perkins, M.D., Roscigno, G. and Zumla, A. Progress towards improved tuberculosis diagnostics for developing countries. Lancet. 2006; 367: 942 - 943 
7. Perkins, M.D., Conde, M.B., Martins, M. and Kritski, A.L. Serologic diagnosis of tuberculosis using a simple commercial multi antigen assay Chest .2003; 123: $107-112$.

8. Steingart, K. R., Dendukuri, N., Henry, M., Schiller, I., Nahid, P., Hopewell, P. C., Ramsay, A., Pai, M. and Laal, S. Performance of purified antigens for serodiagnosis of pulmonary tuberculosis: a meta-analysis. Clinical and Vaccine Immunology .2009;16(2): 260 - 276

9. Enwuru, C.A., Idigbe, E.O., Ezeobi, N.V., Oparaugo, C.T., Udensi, K. U., Onyewuche, J.I. and Ibiam, J. Comparative Study on Specific and Early Detection of Pulmonary Mycobacteria Complex using smear and culture methods and serological Pathozyme EIA kits. African Journal of Clinical and Experimental Microbiology. 2004; 5(2): 182 - 188.

10. Ohanu, M. E., Okonkwo, P. O., Aghaji, M., Njeze, N., Nwokocha, A. and Ele, E. Diagnosis of Tuberculosis: Experience with use of an Immunochromatographic Assay in a Nigerian Hospital. Journal of College of Medicine. 2004; 9(1): 42 - 44.
11. Kassa-Kelembho, E., Kassa, E., Zandanga, G., Service Y-B., Ignaleamoko, A. and Talarmin, A. Poor performance of a Novel Serological Test for Diagnosis of Pulmonary Tuberculosis in Bangui, Central African Republic Clinical and Vaccine Immunology. 2006; 13(6): 702 $-703$.

12. Pottumarthy, S., Wells, V.C. and Morris, A.J. A comparison of seven tests for serological diagnosis of tuberculosis Journal of Clinical Microbiology. 2000; 38: 2227-2231

13. WHO/TDR. Laboratory-based evaluation of 19 commercially available rapid diagnostic tests for tuberculosis (Diagnostics Evaluation Series, No. 2) .2008; WHO, Geneva, Switzerland.

14. Anderson, B. L., Welch, R. J. and Litwin, C. M.. Assessment of three commercially available serologic assays for detection of antibodies to Mycobacterium tuberculosis and identification of active tuberculosis. Clinical and Vaccine Immunology. 2008; 15(11): 1644 - 1649. 